\title{
Effect of Air Quality on Cardio-Respiratory Systems in Northern Thailand (Chiang Mai, Chiang Rai and Nan Province)
}

\author{
Ketwarang Leelasittikul, Patcharee Koonkumchoo, \\ Sasipa Buranapuntalug, \\ Karan Pongpanit, and Kornanong Yuenyongchaiwat*
}

\begin{abstract}
Department of Physiotherapy, Faculty of Allied Health Sciences, Thammasat University, Pathumthani 12120, Thailand
\end{abstract}

*Corresponding author.E-mails:ykornano@tu.ac.th,Kornanong.y@allied.tu.ac.th https//:doi.org/10.12982/CMUJNS.2020.0045

Received: November 1, 2019

Revised: December 5, 2019

Accepted: December 12, 2019

\begin{abstract}
Poor air quality is an important problem in several countries, especially in northern Thailand. Several studies have reported the association between these problems and risks of human health. However, little is known regarding the effects of the air quality on cardio-respiratory systems among people of different ages. The aim of this study is to compare the effects of air quality on pulmonary function and cardiovascular endurance before high PM10, high $P M_{10}$, and after high PM $M_{10}$ periods in children, adults and elderly groups in the north of Thailand. A prospective cohort study with three different periods was designed. A sample of 450 participants (i.e., children, adults, and elderly people) was random, and were recruited in Chiang Rai, Chiang Mai, and Nan. Pulmonary function tests and cardiovascular endurance were measured by spirometer and six-minute walk distance (6MWD), respectively. A total of 335 participants were recruited; 96 children, 119 adults and 120 elderly people. For pulmonary function, force expiratory volume in first second/Force vital capacity (FEVI/FVC) in the children's group found significant differences when compared before high PM10 - high PM10 period (D 2.289\%) and before high PM $M_{10}$ - after high PM 10 period (D2.324\%). Also, 6MWD found significant differences in children, adults, and elderly groups when compared before high

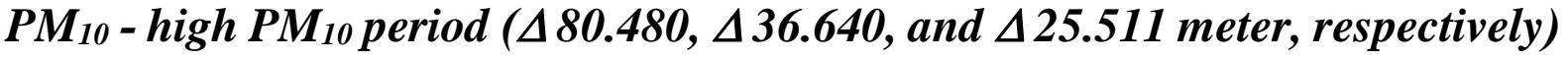
and before high PM10 - after high PM10 period $(\Delta 70.488, \Delta 22.874$, and $\Delta$ 16.374 meter, respectively). Therefore, air quality had a negative effect on the cardiorespiratory system.
\end{abstract}

Keywords: Air pollution, $\mathrm{PM}_{10}$, Climate change, Health risk assessment 


\section{INTRODUCTION}

Poor air quality is a significant public health problem in several countries including the northern part of Thailand. Northern Thailand faces problems with the haze problem (i.e., air pollution) due to the landscape of the north, which is a mountainous and pan-area. Further, haze might be released from neighboring countries and transported in the atmosphere resulting in increased air pollution (Vichit-Vadakan and Vajanapoom, 2011). The main causes of haze and air pollution are forest fires and the burning of agricultural materials. The Department of National Parks Wildlife and Plant Conservation in 2016 reported that the number of fires was 6,685 and the damaged areas was 112,523.90 Rai from $1^{\text {st }}$ October 2005 to $24^{\text {th }}$ May 2016 (Forest Fire Control Division National Park, 2016). In addition, the northern part of Thailand usually faces haze and air pollution problems in particular Chiang Mai, Chiang Rai, Mae Hong Son, and Nan.

Substances in the haze and air pollution are many, but include Sulfur dioxide $\left(\mathrm{SO}_{2}\right)$, Nitrogen dioxide $\left(\mathrm{NO}_{2}\right)$, Carbon monoxide $(\mathrm{CO})$, Ozone $\left(\mathrm{O}_{3}\right)$, especially Particulate matter (PM) (Brook et al., 2010; Wang et al., 2016). A large amount of exposure leads to decreased pulmonary function, increased risk of respiratory symptoms, airway inflammation, and fibrosis of lungs (Liu et al., 2016). Moreover, $\mathrm{CO}$ can combine with hemoglobin in the blood ( $\mathrm{HbCO}$ ). These prevent hemoglobin from carrying oxygen to the tissues, effectively reducing the oxygen-carrying capacity of the blood (Townsend et al., 2002). Besides, PM could be absorbed into lungs and caught in the small airways and alveoli (Nemmar et al., 2002; Lu et al., 2013). Moreover, exposure to particulate air pollutants (e.g., Particulate Matter with a diameter smaller than $10 \mu \mathrm{m}$ : $\mathrm{PM}_{10}$ ) related to health problems such as increased mortality rate, decreased life expectancy, and increased respiratory and cardiovascular symptoms in acute and chronic exposures (Pope et al., 2004; He et al., 2010; Karakatsani et al., 2012; Roy et al., 2012; Pothirat et al., 2019a; Pothirat et al., 2019b). A recent study in Thailand has reported that $\mathrm{PM}_{10}$ was associated with acute respiratory syndrome (i.e, exacerbation of chronic obstructive pulmonary disease) from data records in hospital (Pothirat et al., 2019a). In addition, $\mathbf{P M}_{10}$ are also a risk of daily mortality and causes of death from respiratory disease (i.e., chronic obstructive pulmonary disease) and cardiovascular disease (i.e., coronary artery disease) in Chiang Mai, Thailand (Pothirat et al., 2019b). However, the majority of these reports were extracted from the National centre for health Statistics or data from hospitals. A few studies examined the health impact of exposure in different participants and in different times within the same study. Therefore, this study focused on the health impacts of the air quality on the cardio-respiratory systems in term of pulmonary function and cardiovascular endurance in the three different time periods (i.e., before high $\mathrm{PM}_{10}$ period, high $\mathrm{PM}_{10}$ period, and after high $\mathrm{PM}_{10}$ period) in children, adults, and elderly groups who live in northern Thailand. 


\section{METHODS}

A prospective cohort study was designed with three durations; before high $\mathrm{PM}_{10}$ period, high $\mathrm{PM}_{10}$ period, and after high $\mathrm{PM}_{10}$ period in different three areas in the northern part of Thailand.

Generally, there is no criteria for selecting episodic values from a monitoring site database (Reizer and Juda-Rezler, 2016). Therefore, the present study has given the definition of a high $\mathrm{PM}_{10}$ period by a period of a high concentration $\mathrm{PM}_{10}$ levels during the last five years. According to the Pollution Control Department data during five years; between 2012 and 2016), high $\mathrm{PM}_{10}$ period is approximately between in March and April. Therefore, the data was collected in April (as a high $\mathrm{PM}_{10}$ ). Before high $\mathrm{PM}_{10}$ period was defined as before in March and after high $\mathrm{PM}_{10}$ period was defined as after in April. Thus, before high $\mathrm{PM}_{10}$ period, the data was collected from December $11^{\text {st }}$ to $29^{\text {th }}, 2016$. High PM10 period was recruited during April $18^{\text {th }}$ to $27^{\text {th }}, 2017$, and after high $\mathrm{PM}_{10}$ period was recruited during June $19^{\text {th }}$ to $27^{\text {th }}, 2017$. According to the report from The Pollution Control Department in 2012-2016, it was found that Chiang Mai, Chiang Rai, and Nan provinces had air population problems, in particular haze (Figure 1). So, air quality monitoring sites were set up in Chiang Mai at Mae Chaem district and Meuang district, Chiang Rai at Mae Sai district and Meuang district, and Nan province at Chaloem Phra Kiat district and Meuang district (The Pollution Control Department, 2016). In addition, the local meteorological instruments are used in these district's areas. Therefore, these areas were explored to monitor $\mathrm{PM}_{10}, \mathrm{CO}$, and air quality index (AQI) and also determined the health effect of haze on cardio-respiratory systems.
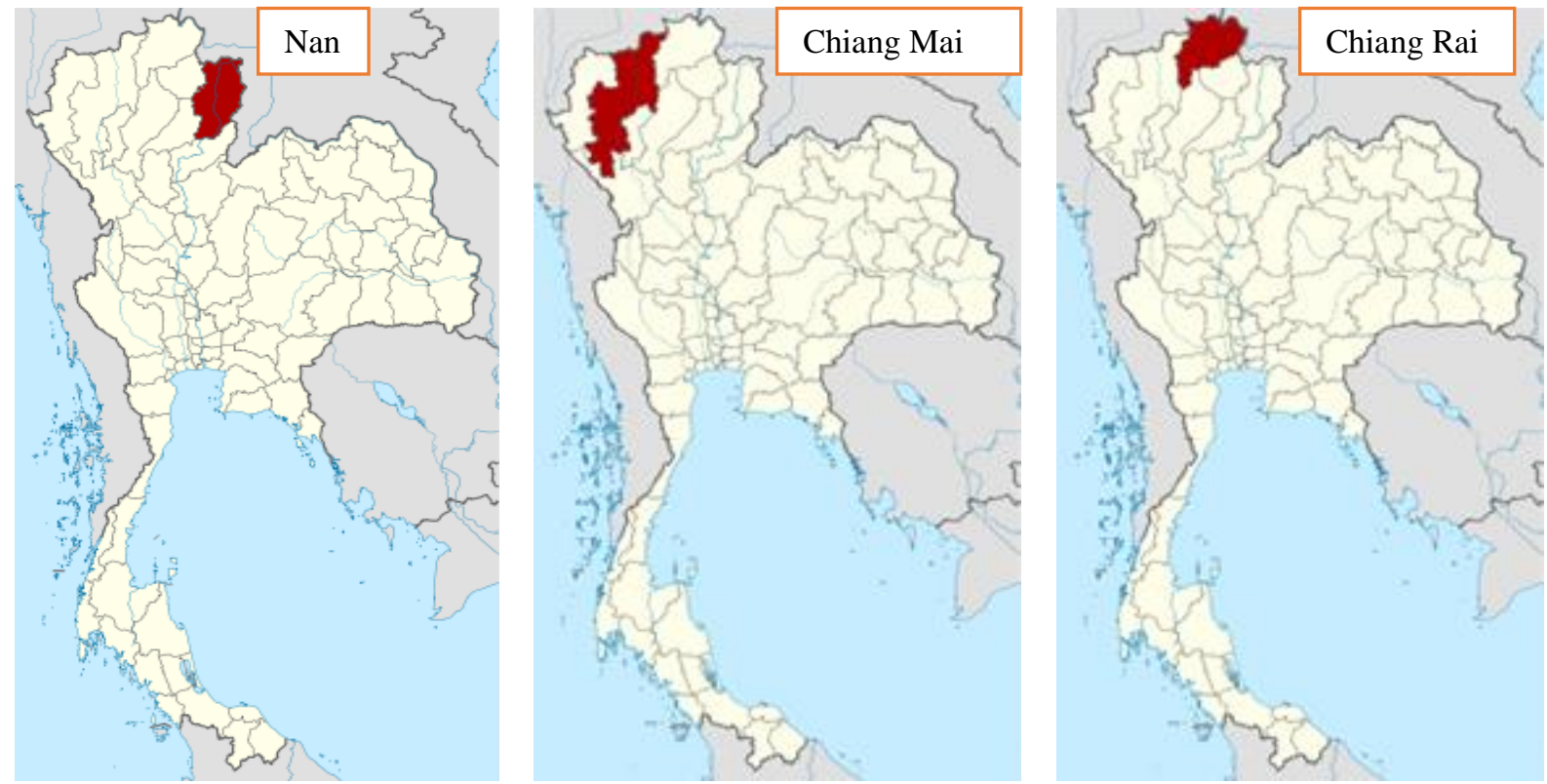

Figure 1. City map in Northern Thailand. 
Three provinces in the northern part of Thailand were selected because of a high prevalence of $\mathrm{PM}_{10}$. Participants who were living in Chiang Mai (Mae Chaem district and Meuang district, Chiang Rai (i.e., Mae Sai district and Meuang district), and Nan provinces (i.e, Chaloem Phra Kiat district and Meuang district) were invited to the study. No-one has researched the overall effects of the different levels of air pollution (before high $\mathrm{PM}_{10}$, during $\mathrm{PM}_{10}$ and after high $\mathrm{PM}_{10}$ ) on the different age groups within a given population. Therefore, the sample size calculations were set as an effect size was 0.2 and the sufficient power was $80 \%$. Therefore, 54 participants in six areas were recruited. However, to prevent the drop out, 75 participants in each area were recruited (Chiang Mai province at Meuang district and Mae Chaem district, Chiang Rai province at Meuang district and Mae Sai district, and Nan province at Meuang district and Chaloem Phra Kiat district). A 150 participants in the children's group (aged between 10-15 years old), 150 participants in the adult's groups (aged between 18-59 years old), and 150 participants in the elderly group (aged $\geq 60$ years old) were examined. These participants were able to understand and communicate with Thai language. However, participants with unstable angina, recent myocardial infarction, pulmonary embolus, resting heart rate $>120$ beat per minute., systolic blood pressure $>180 \mathrm{mmHg}$ or/and diastolic blood pressure $>100 \mathrm{mmHg}$ were excluded. In addition, participants who had been diagnosed with a neurological disease, musculoskeletal disease that might interfere with test performances, and pregnant woman were also excluded from this study. All participants were asked to complete an informed consent before starting of the study. The study protocol approval was obtained from the Ethics Committee of Thammasat University.

Pulmonary function test was performed by Spirometer (MicroLab $^{\mathrm{TM}}$ spirometer, CareFusion Company, United Kingdom). The protocol was followed from the American Thoracic Society (ATS) (Miller, 2005). Briefly, the participants were asked to blow out into the tube as hard and fast and then keep exhale for at least six seconds. Force vital capacity (FVC), force expiratory volume in first second $\left(\mathrm{FEV}_{1}\right)$, ratio of force expiratory volume in first second and force vital capacity $\left(\mathrm{FEV}_{1} / \mathrm{FVC}\right)$, and peak expiratory flow (PEF) were recorded. Moreover, the six-minute walk test (6MWT) was performed for evaluation cardiovascular endurance. The protocol was followed from the ATS (American Thoracic Society, 2002) and distance for 6MWT was recorded. Shortly, all participants were instructed to walk 30 meters along a straight corridor for 6 minutes. Heart rate, blood pressure, oxygen saturation and rate of perceived of exertion were performed before and after the tests. Distances from 6 minutes were then recorded. In the study, the $\mathrm{PM}_{10}, \mathrm{CO}$ and AQI episode values were defined as a situation with the average daily these concentrations at air quality monitoring sites. Information on air quality was obtained from reporting of The Pollution Control Department. Data on $\mathrm{PM}_{10}$, CO, and AQI were then recorded. 
The SPSS version 22.0 was used for analysis. A $p$-value was set at less than 0.05. Repeated measure ANOVA tests and Bonferroni post-hoc tests were conducted to compare whether the health impacts on cardio-respiratory systems (e.g., pulmonary function and six-minute walk distance (6MWD)) in three different situations (before high $\mathrm{PM}_{10}$, high $\mathrm{PM}_{10}$, and after high $\mathrm{PM}_{10}$ ) and were conducted to compare pollutant concentrations in three different situations.

\section{RESULTS}

The study was performed in six districts within three provinces in the northern part of Thailand; Chiang Mai (Meuang district and Mae Chaem district), Chiang Rai (Meuang district and Mae Sai district), and Nan (Meuang district and Chaloem Phra Kiat district). In three different periods, 450 participants were recruited at baseline in the study. They were composed of 150 participants in each group (i.e., children, adults, and elderly people). However, 115 participants (26\%) dropped out from the study (52 participants were busy, 14 participants were sick, eight participants moved out, 40 participants could not be contacted, and one participant died). Therefore, only 335 participants (74\%) participated in this study (Figure 2).

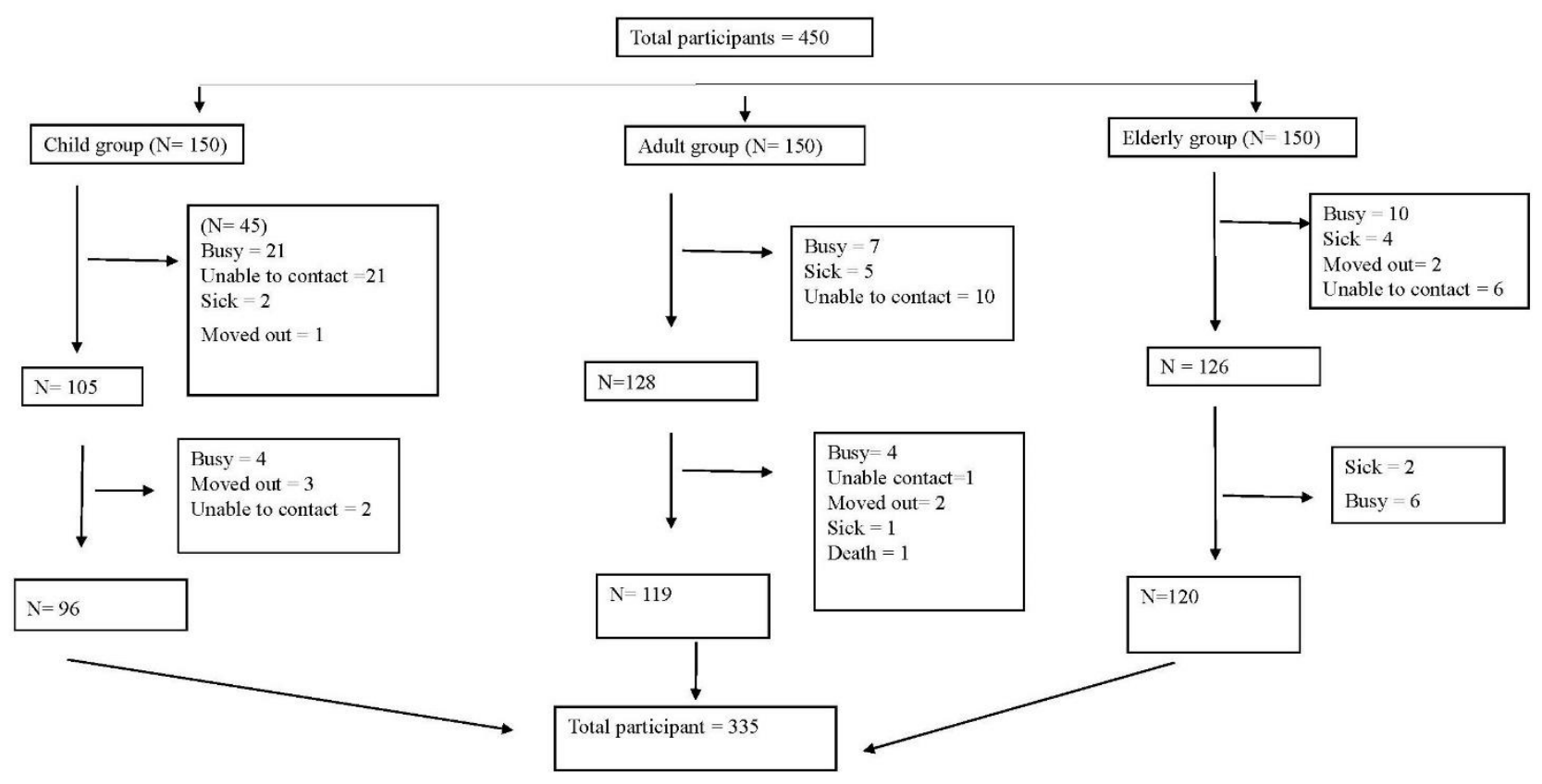

Figure 2. Schematic of study protocol.

The study consisted of 96 participants in the children's group (mean aged $12.33 \pm 1.45$ years), 119 participants in the adult's group (mean aged $43.23 \pm 10.19$ years), and 120 participants in the elderly group (mean aged $69.58 \pm 7.93$ years). Table 1 displays baseline health and general information in children, adults, and elderly participants. 
Table 1. Means, standard deviations, and percentage of participant's general characteristics in children, adults, and elderly groups.

\begin{tabular}{lccc}
\hline \multicolumn{1}{c}{ Characteristics } & $\begin{array}{c}\text { Children group } \\
(\mathbf{n}=\mathbf{9 6})\end{array}$ & $\begin{array}{c}\text { Adults group } \\
(\mathbf{n}=\mathbf{1 1 9})\end{array}$ & $\begin{array}{c}\text { Elderly group } \\
(\mathbf{n}=\mathbf{1 2 0})\end{array}$ \\
\hline Sex & & & \\
$-\quad$ Male (\%) & $45(46.88 \%)$ & $40(33.61 \%)$ & $37(30.83 \%)$ \\
- Female (\%) & $51(53.12 \%)$ & $79(66.39 \%)$ & $83(69.17 \%)$ \\
Age (years) & $12.33 \pm 1.45$ & $43.23 \pm 10.19$ & $69.58 \pm 7.93$ \\
BMI (kg./m²) & $18.97 \pm 4.50$ & $23.86 \pm 3.87$ & $22.89 \pm 4.16$ \\
Duration of living (years) & $11.13 \pm 2.88$ & $32.01 \pm 13.80$ & $54.87 \pm 19.18$ \\
Underlying diseases & & & \\
- No (\%) & $86(89.58 \%)$ & $91(76.47 \%)$ & $48(82.33 \%)$ \\
-Yes (\%) & $10(10.42 \%)$ & $28(23.53 \%)$ & $72(17.67 \%)$ \\
- Respiratory diseases (\%) & $7(70.00 \%)$ & $3(7.50 \%)$ & $3(3.49 \%)$ \\
- Cardiovascular diseases (\%) & $0(0.00 \%)$ & $0(0.00 \%)$ & $0(0.00 \%)$ \\
- Hypertension (\%) & $0(0.00 \%)$ & $14(35.00 \%)$ & $58(67.44 \%)$ \\
- Dyslipidemia (\%) & $0(0.00 \%)$ & $10(25.00 \%)$ & $8(9.30 \%)$ \\
- Diabetes mellitus (\%) & $0(0.00 \%)$ & $4(10.00 \%)$ & $12(13.95 \%)$ \\
- Others diseases (\%) & $3(30.00 \%)$ & $9(22.50 \%)$ & $5(5.82 \%)$ \\
\hline
\end{tabular}

The averages of $\mathrm{PM}_{10}, \mathrm{CO}$ in the atmosphere, and $\mathrm{AQI}$ in three different periods; before high $\mathrm{PM}_{10}$ period, high $\mathrm{PM}_{10}$ period, and after high $\mathrm{PM}_{10}$ period were presented in Figure 3-5. $\mathrm{PM}_{10}, \mathrm{CO}$ in the atmosphere, and AQI found statistically significant differences when compared before high $\mathrm{PM}_{10}$ period high $\mathrm{PM}_{10}$ period and in another time (high $\mathrm{PM}_{10}$ period - after high $\mathrm{PM}_{10}$ period) $(P<0.001)$. Moreover, $\mathrm{PM}_{10}$ and AQI found statistically significant differences when compared before high $\mathrm{PM}_{10}$ period - after high $\mathrm{PM}_{10}$ period $(P<0.001)$.

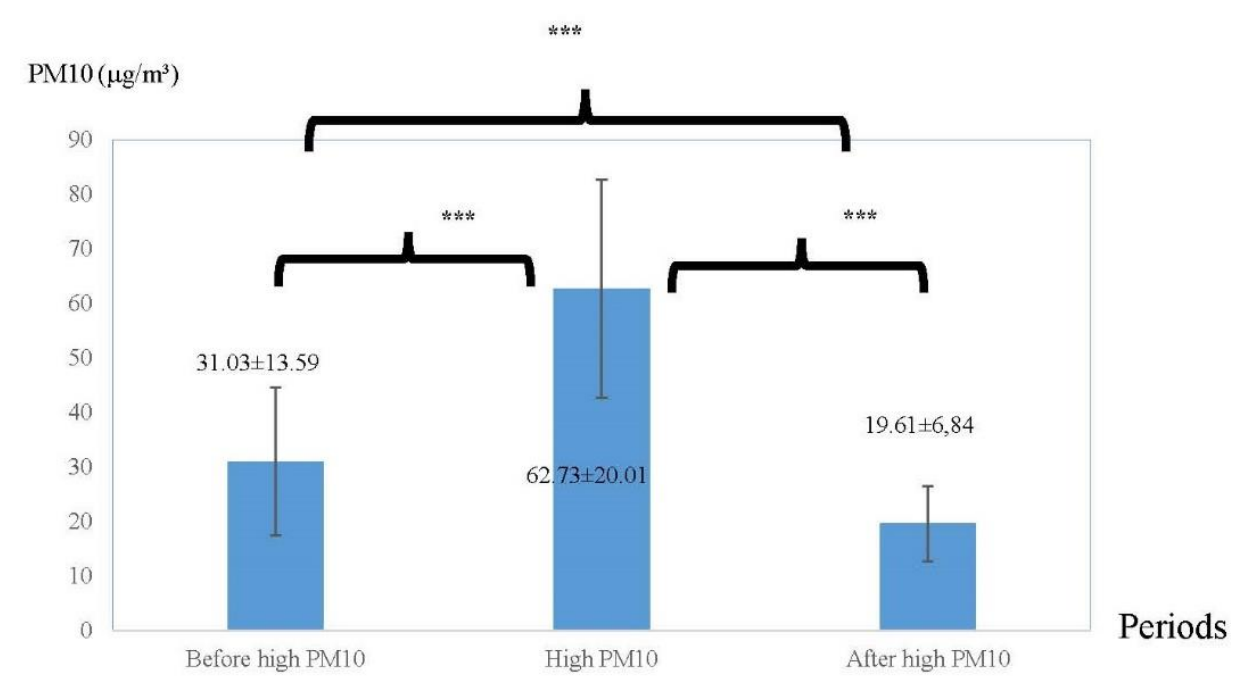

Figure 3. The averages of $\mathrm{PM}_{10}$ in three different periods: before high $\mathrm{PM}_{10}$ period, high $\mathrm{PM}_{10}$ period, and after high PM. 


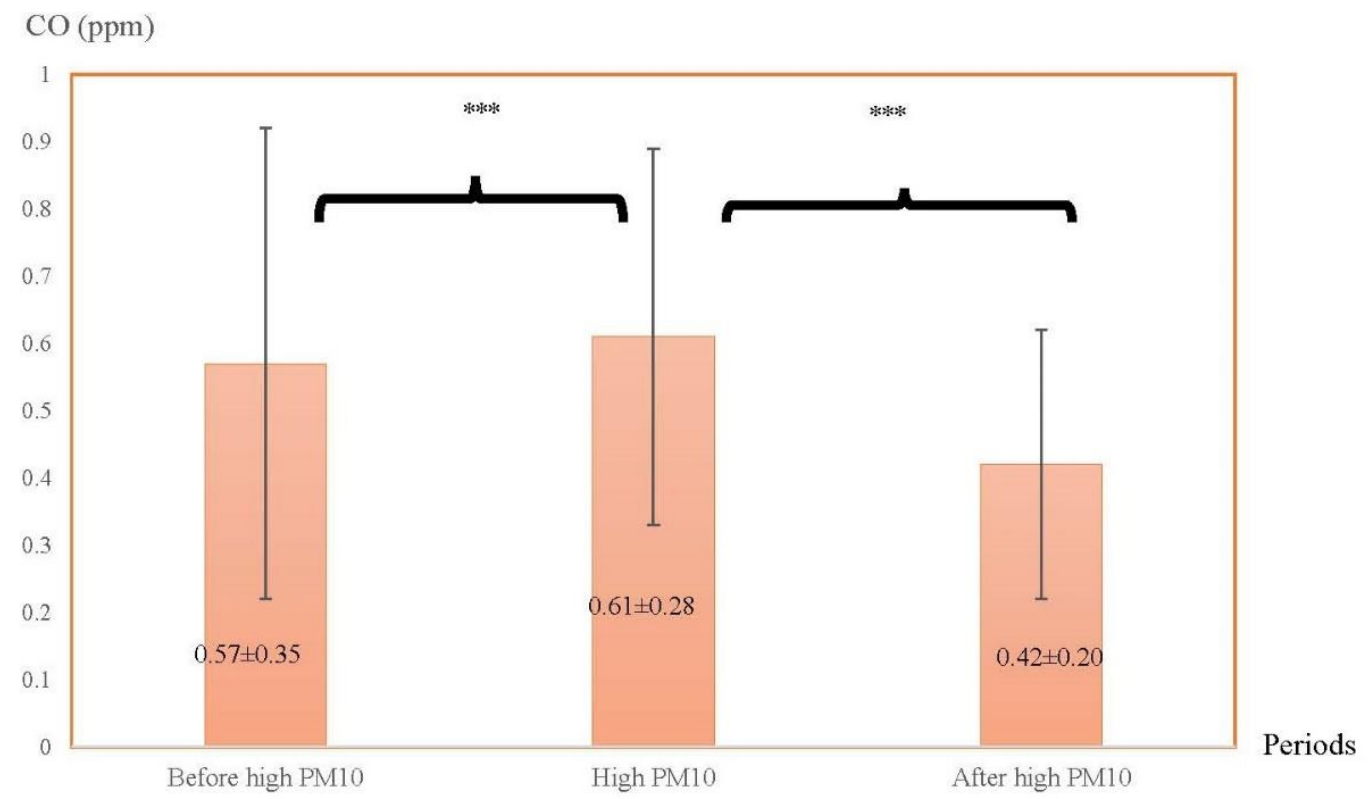

Figure 4. The averages of $\mathrm{CO}$ in three different periods: before high $\mathrm{PM}_{10}$ period, high $\mathrm{PM}_{10}$ period, and after high $\mathrm{PM}_{10}$ period.

Note: ${ }^{* * *}$ indicated $P<0.001$.

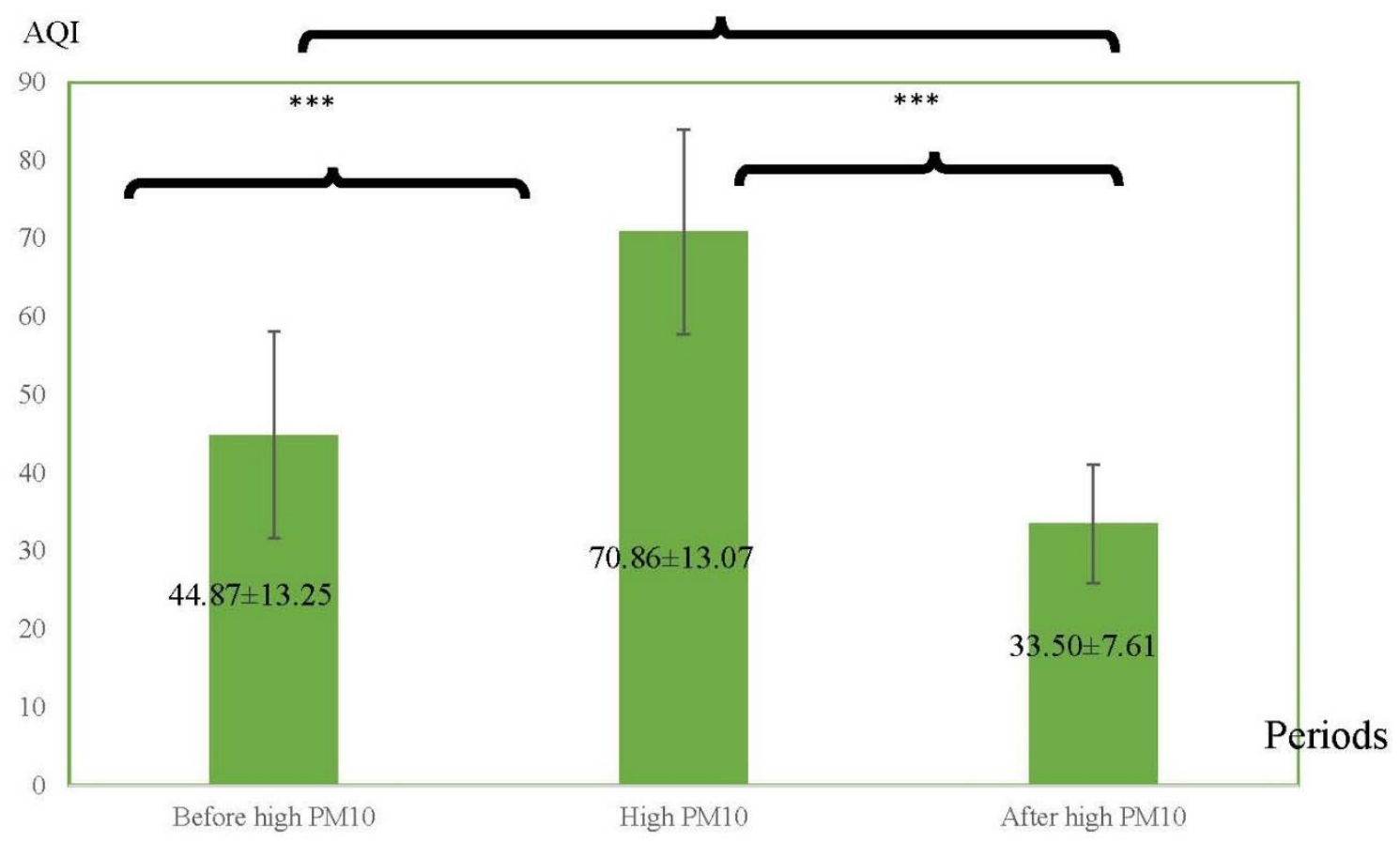

Figure 5. The averages of $\mathrm{AQI}$ in three different periods: before high $\mathrm{PM}_{10}$ period, high $\mathrm{PM}_{10}$ period, and after high $\mathrm{PM}_{10}$ period.

Note: ${ }^{* * *}$ indicated $P<0.001$. 
Pulmonary function in three different periods: before high $\mathrm{PM}_{10}$ period, high $\mathbf{P M}_{10}$ period, and after high $\mathrm{PM}_{10}$ period in children, adults, and elderly groups.

Mean values and standard deviation of pulmonary function in the children's, adult's, and elderly groups are displayed in the Table 2.

In children group, FVC was found statistically significant differences when compared in three different periods (between before high $\mathrm{PM}_{10}$ period - high $\mathrm{PM}_{10}$ period, high $\mathrm{PM}_{10}$ period - after high $\mathrm{PM}_{10}$ period, and before high $\mathrm{PM}_{10}$ period after high $\mathrm{PM}_{10}$ period were $-0.123 \mathrm{~L} ; P<0.001,-0.043 \mathrm{~L} ; P=0.020$, and -0.166 $\mathrm{L} ; P<0.001$ respectively). Besides, $\mathrm{FEV}_{1} / \mathrm{FVC}$ found statistically significant differences when compared before high $\mathrm{PM}_{10}$ period - high $\mathrm{PM}_{10}$ period $(\Delta$ $2.289 \% ; P=0.048$ ) and in another time (before high $\mathrm{PM}_{10}$ period - after high $\mathrm{PM}_{10}$ period) $(\triangle 2.324 \% ; P=0.017)$. However, $\mathrm{FEV}_{1}$ and $\mathrm{PEF}$ found no significant differences when compared before high $\mathrm{PM}_{10}$ period - high $\mathrm{PM}_{10}$ period $(P>0.05)$.

Also, in the adults and elderly groups, there were no significant differences in all variables of pulmonary function when compared before high $\mathrm{PM}_{10}$ period high $\mathrm{PM}_{10}$ period $(P>0.05)$.

Cardiovascular endurance in three different periods: before high $\mathbf{P M}_{10}$ period, high $\mathrm{PM}_{10}$ period, and after high $\mathrm{PM}_{10}$ period in the children's, adult's, and elderly groups.

6MWD has been indicated in cardiovascular endurance. The results found that 6MWD was found statistically significant differences when compared before high $\mathrm{PM}_{10}$ period - high $\mathrm{PM}_{10}$ period and in another time (high $\mathrm{PM}_{10}$ period - after high $\mathrm{PM}_{10}$ period) in children group $(\Delta 80.480 \mathrm{~m} ; P<0.001$ and $\Delta 70.488 \mathrm{~m}$; $P<0.001$ respectively), adults group $(\Delta 36.640 \mathrm{~m} ; P<0.001$ and $\Delta 22.874 \mathrm{~m}$; $P=0.003$ respectively), elderly group $(\triangle 25.511 \mathrm{~m} ; P<0.001$ and $16.374 \mathrm{~m}$; $P=0.027$ ) (Table 2). 
Table 2. Pulmonary function and cardiovascular endurance in three different periods: before high $\mathrm{PM}_{10}$ period, high $\mathrm{PM}_{10}$ period, and after high $\mathrm{PM}_{10}$ period in children, adults, and elderly groups.

\begin{tabular}{|c|c|c|c|c|c|c|c|}
\hline \multirow[t]{2}{*}{ Age groups } & \multirow[t]{2}{*}{ Variables } & \multicolumn{3}{|c|}{ Mean \pm SD } & \multirow[t]{2}{*}{$P$-value ${ }^{a}$} & \multirow[t]{2}{*}{$P$-value ${ }^{b}$} & \multirow[t]{2}{*}{$P$-value ${ }^{c}$} \\
\hline & & $\begin{array}{l}\text { Before high } \\
\text { PM}_{10} \text { period }\end{array}$ & $\begin{array}{l}\text { High PM10 } \\
\text { period }\end{array}$ & $\begin{array}{l}\text { After high } \\
\text { PM }_{10} \text { period }\end{array}$ & & & \\
\hline \multirow{5}{*}{$\begin{array}{l}\text { Children } \\
(\mathrm{n}=96)\end{array}$} & -FVC (Liter) & $2.36 \pm 0.07$ & $2.48 \pm 0.07$ & $2.52 \pm 0.07$ & $<0.001^{* *}$ & $0.020^{*}$ & $<0.001^{* *}$ \\
\hline & $-\mathrm{FEV}_{1}$ (Liter) & $2.17 \pm 0.06$ & $2.23 \pm 0.06$ & $2.26 \pm 0.06$ & 0.333 & 0.532 & $0.019^{*}$ \\
\hline & $-\mathrm{FEV}_{1} / \mathrm{FVC}(\%)$ & $92.48 \pm 0.64$ & $90.19 \pm 0.96$ & $90.16 \pm 0.90$ & $0.048^{*}$ & 1.000 & $0.017^{*}$ \\
\hline & $\begin{array}{l}-\mathrm{PEF} \\
(\mathrm{Liter} / \mathrm{min})\end{array}$ & $232.46 \pm 7.58$ & $221.57 \pm 7.72$ & $233.13 \pm 8.16$ & 0.428 & 0.214 & 1.000 \\
\hline & -6MWD (Meter) & $559.16 \pm 6.11$ & $478.68 \pm 5.85$ & $488.67 \pm 6.65$ & $<0.001^{* *}$ & 0.631 & $<0.001^{* *}$ \\
\hline \multirow{5}{*}{$\begin{array}{c}\text { Adults } \\
(\mathrm{n}=119)\end{array}$} & -FVC (Liter) & $2.72 \pm 0.07$ & $2.72 \pm 0.07$ & $2.70 \pm 0.06$ & 1.000 & 0.749 & 1.000 \\
\hline & $-\mathrm{FEV}_{1}$ (Liter) & $2.42 \pm 0.06$ & $2.41 \pm 0.06$ & $2.39 \pm 0.06$ & 1.000 & 0.875 & 0.073 \\
\hline & $-\mathrm{FEV}_{1} / \mathrm{FVC}(\%)$ & $89.58 \pm 0.55$ & $88.15 \pm 0.57$ & $88.43 \pm 0.56$ & 0.075 & 1.000 & 0.074 \\
\hline & $\begin{array}{l}\text {-PEF } \\
\text { (Liter/min) }\end{array}$ & $\begin{array}{c}295.72 \pm \\
10.50\end{array}$ & $\begin{array}{c}284.39 \pm \\
11.09\end{array}$ & $\begin{array}{c}272.21 \pm \\
10.59\end{array}$ & 0.456 & 0.329 & $0.011^{*}$ \\
\hline & -6MWD (Meter) & $492.26 \pm 5.58$ & $455.62 \pm 5.36$ & $469.39 \pm 6.57$ & $<0.001^{* *}$ & 0.196 & $0.003^{*}$ \\
\hline \multirow{5}{*}{$\begin{array}{l}\text { Elderly } \\
(\mathrm{n}=120)\end{array}$} & -FVC (Liter) & $1.90 \pm 0.05$ & $1.93 \pm 0.05$ & $1.95 \pm 0.05$ & 0.700 & 1.000 & 0.205 \\
\hline & $-\mathrm{FEV}_{1}$ (Liter) & $1.61 \pm 0.05$ & $1.61 \pm 0.04$ & $1.61 \pm 0.04$ & 1.000 & 1.000 & 1.000 \\
\hline & $-\mathrm{FEV}_{1} / \mathrm{FVC}(\%)$ & $84.74 \pm 0.96$ & $84.44 \pm 1.00$ & $83.48 \pm 0.89$ & 1.000 & 1.000 & 0.543 \\
\hline & $\begin{array}{l}-\mathrm{PEF} \\
(\text { Liter/min) }\end{array}$ & $189.90 \pm 8.42$ & $188.92 \pm 7.53$ & $180.79 \pm 8.05$ & 1.000 & 0.639 & 0.576 \\
\hline & -6MWD (Meter) & $373.71 \pm 7.89$ & $348.20 \pm 7.80$ & $357.34 \pm 8.35$ & $<0.001^{* *}$ & 0.347 & $0.027^{*}$ \\
\hline \multicolumn{8}{|c|}{$\begin{array}{l}\text { Note: }{ }^{a} P \text {-value from the repeated measure ANOVA when compared during before high } \mathrm{PM}_{10} \text { period - high } \\
\mathrm{PM}_{10} \text { period. }\end{array}$} \\
\hline
\end{tabular}

\section{DISCUSSION}

The study provides evidence that haze and air pollution or air quality associated with increased risk of pulmonary function, as measured by $\mathrm{FEV}_{1} / \mathrm{FVC}$ in the children's group and cardiovascular endurance in children's, adult's, and elderly groups.

\section{Pulmonary function}

The results found that FVC in the children's group found statistically significant differences when compared in three different periods. Mean value of FVC in before high $\mathrm{PM}_{10}$ period, high $\mathrm{PM}_{10}$ period, and after high $\mathrm{PM}_{10}$ period were 2.36 liter, 2.48 liter, and 2.52 liter respectively. Some previous studies reported the minimal clinically important difference (MCID) which is the smallest change in a measure. MCID was changed in 2-6\% (du Bois et al., 2011). However, differences of FVC in three periods in this present study was $1.6 \%$. Therefore, FVC in this study was not changed in clinical practice.

Pulmonary obstructive has been defined as $\mathrm{FEV}_{1} / \mathrm{FVC}$ (He et al., 2010). The study found that in the children's group found statistically significant 
differences when compared before high $\mathrm{PM}_{10}$ period - high $\mathrm{PM}_{10}$ period and in another time (before high $\mathrm{PM}_{10}$ period - after high $\mathrm{PM}_{10}$ period). Mean value of $\mathrm{FEV}_{1} / \mathrm{FVC}$ in before high $\mathrm{PM}_{10}$ period, high $\mathrm{PM}_{10}$ period, and after high $\mathrm{PM}_{10}$ period were $92.48 \%, 90.19 \%$, and $90.16 \%$ respectively. However, $\mathrm{FEV}_{1} / \mathrm{FVC}$ in high $\mathrm{PM}_{10}$ period was less than $\mathrm{FEV}_{1} / \mathrm{FVC}$ in before high $\mathrm{PM}_{10}$ period. This showed a negative trend of obstructive status. Increased pollutants in high $\mathrm{PM}_{10}$ period might be obstructed the air into the lungs. However, air quality in the after high $\mathrm{PM}_{10}$ period returned to good air quality, but $\mathrm{FEV} / \mathrm{FVC}$ in after high $\mathrm{PM}_{10}$ period was not equal to $\mathrm{FEV}_{1} / \mathrm{FVC}$ in before high $\mathrm{PM}_{10}$ period. The possible reason would be the duration from high $\mathrm{PM}_{10}$ period to after high $\mathrm{PM}_{10}$ period, only two months follow-up that might be not enough for a fully recovery.

In addition, $\mathrm{FEV}_{1}$ and PEF in the children's group and all variables of pulmonary function in the adult's and elderly group found no significant differences when compared before high $\mathrm{PM}_{10}$ period - high $\mathrm{PM}_{10}$ period. It might be the concentration of pollutants levels observed in the present study in high $\mathrm{PM}_{10}$ period were relatively lower than the standard level, so statistical analysis did not substantially change the results. However, these were similar to several previous studies (Aekplakorn et al., 2003; Hoek et al., 2012). The results of these studies revealed that there were no significant differences association of pollutants and pulmonary functions. Aekplakorn et al. (2003) examined in the short term exposure, while Hoek et al. (2012) examined in moderate levels of air pollutant. Therefore, short-term exposures to air pollution with low concentration levels might not significantly affect pulmonary function.

However, the present study was inconsistent with several previous studies (Ackermann-Liebrich et al., 1997; Goss et al., 2004; Schikowski et al., 2005; Downs et al., 2007; Kan et al., 2007). These studies showed significant differences in association of pollutants and pulmonary functions. It might be because of collecting data in long term period and high pollutant concentration. For example, Downs et al. (2007) reported participants who had exposure to $\mathrm{PM}_{10}$ displayed a reduction in lung function. They found that the net effect of a decline of $10 \mu \mathrm{g}$ of $\mathrm{PM}_{10}$ per cubic meter over an 11-year period was to reduce the annual rate of decline in $\mathrm{FEV}_{1}$ by $9 \%$ and of $\mathrm{FEF}_{25-75}$ by $16 \%$. However, the mechanism regarding the PM and the human's health (i.e., lung function) are unclear. Some studies suggested that PM might mediate adverse health effects via the generation of reactive oxygen species (Hogervorst et al., 2006; Janssen et al., 2015), activation of cell signaling pathways, and alterations of respiratory tract barrier function and antioxidant defenses, all of which may lead to airway inflammation and changes in pulmonary function (Janssen et al., 2015).

\section{Cardiovascular endurance}

The 6MWT has been useful for measuring in functional capacity. The evidence supports the theory that 6MWT has been associated with cardiovascular disease; shorter walking higher risk of cardiovascular disease (Yap et al., 2015; 
Zotter-Tufaro et al., 2015). The present study found that there were significant differences of $6 \mathrm{MWD}$ when compared before high $\mathrm{PM}_{10}$ period - high $\mathrm{PM}_{10}$ period in children's, adult's, and elderly groups.

A possible reason could be pollutant concentration levels. The air quality index ranges from 0 to more than 300 , with 0 to 50 representing good air quality; 51-100, moderate; 101 to 200, unhealthy; 201 to 300, very unhealthy; and 301 or more, hazardous. A value below 100 has no known health effects for the majority of the healthy human (The Pollution Control Department, 2016). Although air quality in both periods were not effect on human's health, high $\mathrm{PM}_{10}$ period had amount of pollutant concentrations greater than before high $\mathrm{PM}_{10}$ period. Besides, air quality in high $\mathrm{PM}_{10}$ period in this present study was moderate air quality (AQI was 70.26). Exposure to air pollution might be a negative association of air quality index and cardiovascular endurance. Du et al. (2016) reported that PM in air pollution is related to altered vessel functions and increased cardiovascular disease. Further, some studies reported that $\mathrm{O}_{3}$ which is one of air pollutant index induces inflammation in bronchial inflammation (Alexis et al., 2010; Song et al., 2011), affected to difficult breathing (Liu et al., 2016), and resulting to poor physical performance.

Other reasons could be that high $\mathrm{PM}_{10}$ period was in summer season which had high temperature than before high $\mathrm{PM}_{10}$ period (The average highest temperature in before high $\mathrm{PM}_{10}$ period and high $\mathrm{PM}_{10}$ period was approximately $31^{\circ} \mathrm{C}$ and $37^{\circ} \mathrm{C}$ respectively). Some studies suggested that performance capacity might be altered in hot environments (Peiffer and Abbiss, 2011). Also, several previous studies reported that increased temperature could affect to decrease performance capacity (Galloway and Maughan, 1997; Tatterson et al., 2000; Lindemann et al., 2017) due to increases in core temperature, heart rate, rate of perceived exertion, metabolic rate, as well as dehydration (González-Alonso et al., 2008; Tansey and Johnson, 2015). Therefore, the other pollutants or temperature was not accounted for the confounding factors that might be affect cardiovascular endurance; a further study need to explore.

Furthermore, 6MWD was found significant differences when compared before high $\mathrm{PM}_{10}$ period - after high $\mathrm{PM}_{10}$ period. Mean value of $6 \mathrm{MWD}$ in after high $\mathrm{PM}_{10}$ period was less than before high $\mathrm{PM}_{10}$ period. It might be because duration from high $\mathrm{PM}_{10}$ period to after high $\mathrm{PM}_{10}$ period was not enough for recovery.

The present study has several limitations. First, this study collected data over a short time period and the concentration of pollutants observed in the present study was relatively within the standard levels, so some statistical analysis did not substantially change the results. According to the government policy regarding the burning period and intense rain and storms weather during the recruited participants, high air pollution was not noted. Lastly, a small sample size was observed. Therefore, long-term study during high air pollution with a large sample size might confirm whether poor air quality may lead to 
cardiovascular and respiratory systems in different aged with different duration of the study.

\section{CONCLUSION}

A moderate air quality is associated with increased risk of obstructive status and decreased cardiovascular endurance. Regarding the cardiorespiratory perspective within two months of follow-up, these parameters might not have fully recovered. Therefore, people who are at risk of cardiorespiratory disease should be recommended to use a personal protective mask to protect their health from haze. Further, the government should be responsible, for the policies controlling haze and air pollution.

\section{ACKNOWLEDGEMENTS}

The authors would like to express our sincere gratitude to National Research Council of Thailand for funding. Also, special thanks are extended to village leaders of Mae chaem district, Chiang Mai; Muang district, Chiang Mai, Mae Sai district, Chiang Rai; Muang district, Chiang Rai; Chaloem Phra Kiat distric, Nan, and Muang district, Nan for contacting participants in each district to participate in this study. Furthermore, we wish to thank all of the participants who took part in this study.

\section{REFERENCES}

Ackermann-Liebrich, U., Leuenberger, P., Schwartz, J., Schindler, C., Monn, C., Bolognini, G., Bongard, J.P., Brandi, O., Domenighetti, G., Elsasser, S., et al. 1997. Lung function and long term exposure to air pollutants in Switzerland. Study on Air Pollution and Lung Diseases in Adults (SAPALDIA) Team. American Journal of Respiratory and Critical Care Medicine. 155(1):122-129.https://doi.org/10.1164/ajrccm.155.1.900 1300

Aekplakorn, W., Loomis, D., Vichit-Vadakan, N., Shy, C., Wongtim, S., and Vitayanon, P. 2003. Acute effect of sulphur dioxide from a power plant on pulmonary function of children, Thailand. International Journal of Epidemiology. 32(5): 854-861. https://doi.org/10.1093/ije/dyg237

Alexis, N.E., Lay, J.C., Hazucha, M., Harris, B., Hernandez, M.L., Bromberg, P.A., Kehrl, H., Diaz-Sanchez, D., Kim, C., Devlin, R.B., et al. 2010. Low-level ozone exposure induces airways inflammation and modifies cell surface phenotypes in healthy humans. Inhalation Toxicology. 22(7): 593-600. https://doi.org/10.3109/08958371003596587 
American Thoracic Society. 2002. ATS Statement: Guidelines for the six-minute walk test. American Journal of Respiratory and Critical Care Medicine. 166: 111-117. https://doi.org/10.1164/rccm.166/1/111

Brook, R.D., Rajagopalan, S., Pope, C.A., Brook, J.R., Bhatnagar, A., Diez-Roux, A.V., Holguin, F., Hong, Y., Luepker, R.V., Mittleman, M.A., et al. 2010. Particulate matter air pollution and cardiovascular disease: an update to the scientific statement from the American Heart Association. Circulation. 121(21): 2331-2378. https://doi.org/10.1161/CIR.0b013e3181dbece1

du Bois, R.M., Weycker, D., Albera, C., Bradford, W.Z., Costabel, U., Kartashow, A., King, T.E., Jr., Lancaster, L., Noble, P.W., Sahn, S.A., et al. 2011. Forced vital capacity in patients with idiopathic pulmonary fibrosis and minimal clinically important difference. American Journal of Respiratory and Critical Care Medicine. 184(12): 1382-1389. https://doi. org/10.1164/rccm.201105-0840OC

Downs, S.H., Schindler, C., Liu, S., Keidel, D., Bayer-Oglesby, L., Brutsche, M.H., Gerbase, M.W., Keller, R., Kunzli, N., Leuenberger, P., et al. 2007. Reduced exposure to $\mathrm{pm}_{10}$ and attenuated age-related decline in lung function. New England Journal of Medicine. 357: 2338-2347. https://doi.org/10.1056/NEJMoa073625

Du, Y., Xu, X., Chu, M., Guo, Y., and Wang, J. 2016. Air particulate matter and cardiovascular disease: the epidemiological, biomedical and clinical evidence. Journal of Thoracic Disease. 8(1): E8-E19. https://doi.org/ 10.3978/j.issn.2072-1439.2015.11.37

Forest Fire Control Division National Park, 2016. Wildlife and Plant Conservation department. [Internet]. [cited 2016 June 26]. Available from http://www.dnp.go.th/forestfire/2546/firestatistic\%20Th.htm

Galloway, S.D., and Maughan, R.J. 1997. Effects of ambient temperature on the capacity to perform prolonged cycle exercise in man. Medicine and Science in Sports and Exercise. 29(9): 1240-1249. https://doi.org/10.1097/ 00005768-199709000-00018

González-Alonso, J., Crandall, C.G., and Johnson, J.M. 2008. The cardiovascular challenge of exercising in the heat. Journal of Physiology. 586( $\mathrm{Pt} \mathrm{1):} \mathrm{45-}$ 53. https://doi.org/ 10.1113/jphysiol.2007.142158

Goss, C.H., Newsom, S.A., Schildcrout, J.S., Sheppard, L., and Kaufman, J.D. 2004. Effect of ambient air pollution on pulmonary exacerbations and lung function in cystic fibrosis. American Journal of Respiratory and Critical Care Medicine. 169(7): 816-821. https://doi.org/10.1164/rccm.200306$7790 \mathrm{OC}$

He, Q.Q., Wong, T.W., Du, L., Jiang, Z.Q., Gao, Y., Qiu, H., Liu, W.J., Wu, J.G., Wong, A., and $\mathrm{Yu}, \mathrm{T}$.S. 2010. Effects of ambient air pollution on lung function growth in Chinese schoolchildren. Respiratory Medicine. 104(10): 1512-1520. https://doi.org/10.1016/j.rmed.2010.04.016 
Hoek, G., Pattenden, S., Willers, S., Antova, T., Fabianova, E., Braun-Fahrla, C., Forastiere, F., Gehring, U., Luttmann-Gibson, H., Grize, L., et al. 2012. $\mathrm{PM}_{10}$, and children's respiratory symptoms and lung function in the PATY study. European Respiratory Society. 40(3): 538-547. https://doi.org/10. 1183/09031936.00002611

Hogervorst, J.G., de Kok, T.M., Briedé, J.J., Wesseling, G., Kleinjans, J.C., and van Schayck, C.P. 2006. Relationship between radical generation by urban ambient particulate matter and pulmonary function of school children. Journal of Toxicology and Environmental Health, Part A. 69(34): 245-262. https://doi.org/10.1080/15287390500227431

Janssen, N.A.H, Strak, M., Yang, A., Hellack, B., Kelly, F.J., Kuhlbusch, T.A.J., Harrison, R.M., Brunekreel, B., Cassee, F.R., Steenhof, M., et al. 2015. Associations between three specific a-cellular measures of the oxidative potential of particulate matter and markers of acute airway and nasal inflammation in healthy volunteers. Occupational and Environmental Medicine. 72(1): 49-56. https://doi.org/10.1136/oemed-2014-102303

Kan, H., Heiss, G., Rose, K.M., Whitsel, E., Lurmann, F., and London, S.J. 2007. Traffic exposure and lung function in adults: the Atherosclerosis risk in communities study. Thorax 62(10): 873-879. https://doi.org/10.1136/thx. 2006.073015

Karakatsani, A., Analitis, A., Perifanou, D., Ayres, J.G., Harrison, R.M., Kotronarou, A., Kavouras, I.G., Pekkanen, J., Hameri, K., Kos, G.P.A., et al. 2012. Particulate matter air pollution and respiratory symptoms in individuals having either asthma or chronic obstructive pulmonary disease: a European multicentre panel study. Environmental Health. 5: 11-75. https://doi.org/10.1186/1476-069X-11-75

Lindemann, U., Stotz, A., Beyer, N., Oksa, J., Skelton, D.A., Becker, C., Rapp, K. and Klenk, J. 2017. Effect of indoor temperature on physical performance in older adults during days with normal temperature and heat waves. International Journal of Environmental Research and Public Health. 14(2): 186. https://doi.org/10.3390/ijerph14020186

Liu, S., Cai, S., Chen, Y., Xiao, B., Chen, P., and Xiang, X. 2016. The effect of pollutional haze on pulmonary function. Journal of Thoracic Disease. 8(1): E41-56. https://doi.org/10.3978/j.issn.2072-1439.2016.01.18

Lu, K., Qin, Y., He, G.X., and Gao, G.F. 2013. The impact of haze weather on health: A view to future. Biomedical and Environment Sciences. 26(12): 945-946. https://doi.org/10.3967/bes2013.028

Miller, M.R., Hankinson, J., Brusasco, V., Burgos, F., Casaburi, R., Coates, A., Crapo, R., Enright, P., van der Grinten, C.P.M., Gustafsson, P., et al. 2005. Standardisation of spirometry. European Respiratory Journal. 26(2): 319338. https://doi.org/10.1183/09031936.05.00034805 
Nemmar, A., Hoet, P.H., Vanquickenborne, B., Dinsdale, D., Thomeer, M., Hoylaerts, M.F, Vanbilloen, H., Mortelmans, L., and Nemery, B. 2002. Passage of inhaled particles into the blood circulation in humans. Circulation. 105(4): 411-414. https://doi.org/10.1161/hc0402.104118

Peiffer, J.J., and Abbiss, C.R. 2011. Influence of environmental temperature on $40 \mathrm{~km}$ cycling time-trial performance. International Journal of Sports Physiology and Performance. 6(2): 208-220. https://doi.org/10.1123/ ijspp.6.2.208

Pope, C.A., Burnett, R.T., Thurston, G.D., Thun, M.J., Calle, E.E., Krewski, D., Godleski, J.J. 2004. Cardiovascular mortality and long-term exposure to particulate air pollution: epidemiological evidence of general pathophysiological pathways of disease. Circulation. 109(1): 71-77. https://doi.org/10.1161/01.CIR.0000108927.80044.7F

Pothirat, C., Chaiwong, W., Liwsrisakun, C.. Bumroongkit, C., Deesomchok, A., Theerakittikul, T., Limsukon, A., Tajarernmuang, P., and Phetsuk, N. 2019a. The short-term associations of particular matters on non-accidental mortality and causes of death in Chiang Mai, Thailand: a time series analysis study between 2016-2018. International Journal of Environmental Health Research. 1:1-10. https://doi.org/10.1080/09603123.2019.1673883

Pothirat, C., Chaiwong, W., Liwsrisakun, C., Bumroongkit, C., Deesomchok, A., Theerakittikul, T., Limsukon, A., Tajarernmuang, P., and Phetsuk, N. 2019b. Acute effects of air pollutants on daily mortality and hospitalizations due to cardiovascular and respiratory diseases. Journal of Thoracic Disease. 11(7): 3070-3083. https://doi.org/10.21037/jtd. 2019.07.37

Reizer, M., and Juda-Rezler, K. 2016. Explaining the high PM10 concentrations observed in Polish urban areas. Air Quality, Atmosphere and Health. 9: 517-531. https://doi.org/10.1007/s11869-015-0358-z

Roy, A., Hu, W., Wei, F., Korn, L., Chapman, R.S., and Zhang, J.J. 2012. Ambient particulate matter and lung function growth in Chinese children. Epidemiology. 23(3): 464-472. https://doi.org/10.1097/EDE.0b013e31824 cbd6d

Schikowski, T., Sugiri, D., Ranft, U., Gehring, U., Heinrich, J., Wichmann, H., and Kramer, U. 2005. Long-term air pollution exposure and living close to busy roads are associated with COPD in women. Respiratory Research. 6(1): 152. https://doi.org/10.1186/1465-9921-6-152

Song, H., Tan, W., and Zhang, X. 2011. Ozone induces inflammation in bronchial epithelial cells. Journal of Asthma. 48(1): 79-83. https://doi.org/ $10.3109 / 02770903.2010 .529224$

Tansey, E.A., and Johnson, C.D. 2015. Recent advances in thermoregulation. Advances in Physiology Education. 39(3): 139-148. https://doi.org/10. 1152/advan.00126.2014 
Tatterson, A.J., Hahn, A.G., Martini, D.T., and Febbraio, M.A. 2000. Effects of heat stress on physiological responses and exercise performance in elite cyclists. Journal of Science and Medicine in Sport. 3(2): 186-193.

The Pollution Control Department: Thailand's air quality and situation reports. [Internet]. 2016. [cited 2016 July 8]. Available from http://aqnis.pcd.go.th/ data/57

Townsend, C.L., and Maynard, R.L. 2002. Effects on health of prolonged exposure to low concentrations of carbon monoxide. Occupational and Environmental Medicine. 59(10): 708-711. https://doi.org/10.1136/oem. 59.10 .708

Vichit-Vadakan, N., and Vajanapoom, N. 2011. Health impact from air pollution in Thailand: current and future challenges. Environmental Health Perspectives. 119(5): A197-A198. https://doi.org/10.1289/ehp.1103728

Wang, F., Ni, S., and Liu, H. 2016. Pollutional haze and COPD: etiology, epidemiology, pathogenesis, pathology, biological markers and therapy. Journal of Thoracic Disease. 8(1): 20-30. https://doi.org/10.3978/j.issn. 2072-1439.2015.11.62

Yap, J., Lim, F.Y., Gao, F., Teo, L.L., Lam, C.S., Yeo, K.K. 2015. Correlation of the New York Heart Association Classification and the 6-minute walk distance: a systematic review. Clinical Cardiology. 38(10): 621-628. https://doi.org/10.1002/clc.22468

Zotter-Tufaro, C., Mascherbauer, M., Duca, F., Koell, B., Aschauer, S., Kammerlander, A.A., Panzenboeck, A., Sadushi-Kolici, R., Bangert, C., Laimer, D., et al. 2015. Prognostic significance and determinants of the 6min walk test in patients with heart failure and preserved ejection fraction. JACC: Heart Failure 3 (6): 459-466. https://doi.org/10.1016/j.jchf.2015. 01.010 